Article

\title{
Biocatalytic Synthesis of Natural Dihydrocoumarin by Microbial Reduction of Coumarin
}

\author{
Stefano Serra *(D), Antonio Castagna and Mattia Valentino \\ C.N.R. Istituto di Chimica del Riconoscimento Molecolare, Via Mancinelli 7, 20131 Milano, Italy \\ * Correspondence: stefano.serra@cnr.it or stefano.serra@polimi.it; Tel.: +39-02-2399-3076
}

Received: 22 July 2019; Accepted: 31 July 2019; Published: 3 August 2019

\begin{abstract}
Dihydrocoumarin is a natural product of great relevance for the flavour industry. In this work, we describe a study on the biotransformation of the toxic compound coumarin into natural dihydrocoumarin, recognized as safe for food aromatization. To this end, we screened a variety of yeasts and filamentous fungi, isolated from different sources, in order to evaluate their ability to reduce selectively the conjugated double bond of coumarin. Moreover, since coumarin induces cytotoxicity and therefore inhibits cell growth as well as the cell metabolic activity, we tested out different substrate concentrations. All strains were able to convert the substrate, although showing very different conversion rates and different sensitivity to the coumarin concentration. In particular, the yeasts Torulaspora delbrueckii, Kluyveromyces marxianus and the fungus Penicillium camemberti displayed the higher activity and selectivity in the substrate transformation. Among the latter strains, Kluyveromyces marxianus presented the best resistance to substrate toxicity, allowing the biotransformation process even with coumarin concentration up to $1.8 \mathrm{~g} / \mathrm{L}$.
\end{abstract}

Keywords: biotransformation; biocatalysis; coumarin; dihydrocoumarin; natural flavours; yeasts; fungi; whole-cell process; ene-reductase

\section{Introduction}

Coumarin 1 Figure 1 is a natural compound of great relevance in the flavour and fragrance industry [1]. This lactone is one of the first flavours produced by chemical synthesis; it possesses a hay-like, sweet aromatic creamy odour that makes it a suitable ingredient both for food and perfume formulations. Coumarin of natural origin is easily available from the Tonka beans (Dipteryx odorata Willd.) extract, where it is present as the main odorous component [2]. Unfortunately, due to its inherent toxicity, this compound has been banned as a food additive and the growing safety concerns have led the European authority to restrict even the use of natural extracts in which it is present, assessing the tolerable daily intake (TDI) to $0.1 \mathrm{mg} / \mathrm{Kg}$ [3]. Consequently, the identification and the production of natural flavours possessing coumarin like odour, which are considered as safe for human health, have become highly desirable. In this context, the use of dihydrocoumarin 2 as a food-flavouring ingredient has taken a primary role during the last twenty years.
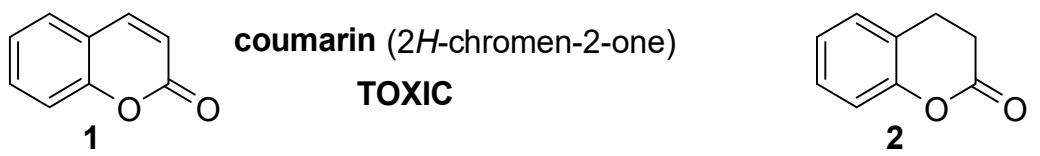
dihydrocoumarin (chroman-2-one) FEMA-GRAS 2381

Figure 1. The coumarin (1) and dihydrocoumarin (2) structures.

The aforementioned lactone has a pleasant sweet, herbaceous, coumarin and coconut-like odor and it has been recognized as safe, being included in the list of the substances Generally Recognized 
As Safe from the Flavor \& Extract Manufacturers Association (FEMA-GRAS), under the number 2381. Although dihydrocoumarin is easily synthesizable by metal-catalyzed hydrogenation of coumarin itself, its availability in natural form is rather limited. In fact, even if this chromanone is a minority component of the Tonka beans extract [2] and has been identified in different vegetal species including sweet clover blossom (Melilotus officinalis) [4], its amount from these sources is largely insufficient to justify an extractive process that could satisfy the growing market request of this natural flavour.

Since the flavours possessing the 'natural' status are usually hundreds times as expensive as their synthetic counterparts, any new procedure that provide these compounds in their high value form can be very profitable. According to the European [5] and USA [6] legislation, the biotransformation of a natural precursor is a 'natural method' of synthesis [7]. Considering that coumarin of natural origin is a quite cheap commodity, the most suitable procedure to synthesize dihydrocoumarin consists in the biocatalyzed reduction of the 3,4 double bond of natural coumarin [8,9]. Several studies have highlighted that this reaction is one of the intermediate steps in the coumarins biodegradation, carried out by filamentous fungi and yeasts [10-14].

In nature, the 'biohydrogenation' of the $\alpha, \beta$-unsaturated esters is performed by ene-reductases, a class of enzymes able to catalyze the asymmetric reduction of the activated C-C double bonds [15]. Different microorganisms can perform this process, in particulars yeasts proved to be the most versatile ones as they can reduce $\alpha, \beta$-unsaturated aldehydes [16-18], ketones and esters [19], including lactones.

Some years ago, during a pioneering study on the stable isotope characterization of ortho-oxygenated phenylpropanoids [8], we prepared dihydrocoumarin through the baker's yeast mediated reduction of coumarin. Since the aim of our work wasn't the large scale preparation of compound 2, we didn't improve our synthetic procedure. Few years later, a research group from Degussa and Technical University of Munich published a relevant paper on the biotechnological production of dihydrocoumarin [9]. According to the reported findings, the latter chromanone was obtained by microbial reduction of natural coumarin using different Saccharomyces cerevisiae strains. Melilotic acid (3) was the main product of the biotransformation that was converted into dihydrocoumarin by simple distillation in the presence of a catalytic amount of citric acid (Figure 2). The same study also underlined the main drawback of the claimed process, namely the high toxicity of coumarin that significantly decreased the yields at a concentration superior to $0.5 \mathrm{~g} / \mathrm{L}$.

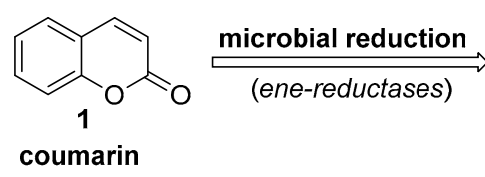

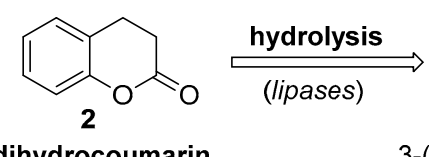

dihydrocoumarin

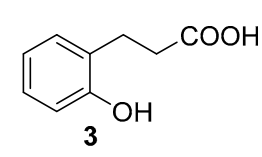

3-(2-hydroxyphenyl)propanoic acid

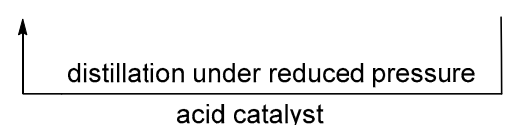

Figure 2. The biocatalysed process for the preparation of natural dihydrocoumarin starting from natural coumarin.

As we recently set up a research program aimed at the biotechnological production of natural flavours [20-26], we decided to design a new process for the preparation of natural dihydrocoumarin based on the microbial reduction of coumarin. To this end, we undertook a comprehensive study intended to select microbial strains showing good tolerance to relatively high coumarin concentrations and that could efficiently perform the reduction of its conjugated double bond.

Herein, we describe the results obtained by our work that, besides confirming and extending those described by previous researches, suggested the prospective utility of the yeasts Torulaspora delbrueckii, Kluyveromyces marxianus and of the fungus Penicillium camemberti for natural dihydrocoumarin production. 


\section{Results and Discussion}

The main problem related with the microbial transformation of coumarin lies in its cytotoxicity that inhibits cell growth along with the cell metabolic activity. In order to select microorganisms able to efficiently perform the coumarin reduction, we defined the following screening conditions.

Each microbial strain of yeasts or filamentous fungi was grown in liquid media, using the universal Medium for Yeasts (YM) or Malt Extract Medium (MEA), respectively. At the end of the exponential growth phase or after complete formation of the filamentous fungi colonies, the cultures were inoculated with the suitable amount of the coumarin, dissolved in dimethyl sulfoxide. The experiments were performed in aerobic conditions, sealing the flasks with cellulose plugs.

To accomplish our study we singled out eighteen different microbial strains. Since we were interested in developing a reliable process for the production of a natural flavour to be used in food, we limited our study to microorganisms belonging to biosafety level 1, with a strong preference with those recognized with technological beneficial use in foods [27]. Accordingly, we preferentially chose microbial species that are currently used as probiotics [28] or for food and flavour processing [29]. We selected Saccharomyces cerevisiae (Type II, from Aldrich), Saccharomyces boulardii (probiotic strain), Komagataella pastoris, Torulaspora delbrueckii, Debaryomyces hansenii and Kluyveromyces marxianus because these yeasts possess the GRAS status and have been already used as whole-cell biocatalysts in a number of studies [30-33]. The yeasts Yarrowia lipolytica, Candida boidinii, Starmerella bombicola and the basidiomycota Xanthophyllomyces dendrorhous, Cryptococcus curvatus and Sporidiobolus johnsonii are oleaginous fungi, industrially used for their ability to degrade/accumulate lipids and have been employed in different flavour production processes [34-37].

Concerning the filamentous fungi, we included in our screening the Ascomycota Aspergillus niger, Geotrichum candidum, Penicillium adametzii, Penicillium corylophilum, Penicillium camemberti and Penicillium roqueforti. The biocatalytic activity of Aspergillus niger was investigated because it has been demonstrated that this microorganism can degrade coumarin and dihydrocoumarin as well as substituted coumarins $[10,11,14]$. Similarly, we singled out Geotrichum candidum, Penicillium adametzii and Penicillium corylophilum since these species are able to reduce the conjugated double bond of different $\alpha, \beta$-unsaturated ketones and lactones [25,38,39]. Finally, we selected two specific strains of Penicillium camemberti and Penicillium roqueforti, which are currently used in the dairy industry. The latter microorganisms, besides possessing the GRAS status, have been already employed for the biotechnological production of flavours [40,41].

Preliminary experiments, in which the transformation of the substrate was checked by sampling the fermentation flasks every $24 \mathrm{~h}$, showed that the reduction of the conjugated double bond did not proceed further after 5-7 days since the substrate addition. From that time onward, the melilotic acid/coumarin ratio kept a constant value. In addition, the Thin Layer Chromatography (TLC) analysis showed only the presence of the melilotic acid and/or of coumarin whereas the concentration of dihydrocoumarin and/or of other metabolites was insignificant, with the single exception of the Aspergillus niger-mediated biotransformation (see below). The Gas Chromatographic analyses using a Mass detector (GC-MS) confirmed these observations although the results were given as a dihydrocoumarin/coumarin ratio, since the melilotic acid is transformed quantitatively into dihydrocoumarin in the GC injector (see experimental).

According to these initial results, we decided to stop all the biotransformation experiments seven days after the coumarin addition and to evaluate the melilotic acid/coumarin ratio using the GC-MS analysis. Since the only biotechnological method of dihydrocoumarin production [9] indicated microbial activity inhibition with a coumarin concentration superior to $0.5 \mathrm{~g} / \mathrm{L}$, we settled a first set of experiments using a starting coumarin concentration of $0.6 \mathrm{~g} / \mathrm{L}$. Depending on the results of the latter screening we decided whether or not the activity of the selected microorganisms should be further studied. Accordingly, microorganisms producing a biotransformation mixture with a melilotic acid/coumarin ratio superior to $40 / 60$ were studied also using a starting substrate concentration of $1.2 \mathrm{~g} / \mathrm{L}$ and $1.8 \mathrm{~g} / \mathrm{L}$. 
The microbial strains affording a melilotic acid/coumarin ratio ranging between 40/60 and 5/95, perform the reduction with unsatisfactory efficiency and thus were not investigated further. Lastly, the microbial strains producing only a trace of compound 3 (melilotic acid/coumarin ratio inferior to 5/95) were employed using a starting coumarin concentration of $0.3 \mathrm{~g} / \mathrm{L}$. The latter biotransformations were executed in order to better understand the reason for the lack of reactivity. In fact, the latter experiments can show whether the strains are unable to perform the reduction or if they gave unsatisfactory results because they were completely inhibited by the substrate toxicity.

Overall, all the results obtained with the above described experiments are collected in Table 1 and allow a number of considerations. First, we can observe that all the selected strains possess the ene-reductase activity, even if its biocatalytic efficiency changes dramatically depending on the microbial strain used and on the coumarin concentration.

Table 1. Results of the microbial biotransformation of coumarin.

\begin{tabular}{|c|c|c|c|c|}
\hline \multirow{3}{*}{ Microorganism } & \multirow{2}{*}{\multicolumn{4}{|c|}{$\begin{array}{c}\text { Dihydrocoumarin/Coumarin Ratio }{ }^{1} \text { (after Seven Days } \\
\text { of Biotransformation) }\end{array}$}} \\
\hline & & & & \\
\hline & $0.3 \mathrm{~g} / \mathrm{L}$ & $0.6 \mathrm{~g} / \mathrm{L}$ & $1.2 \mathrm{~g} / \mathrm{L}$ & $1.8 \mathrm{~g} / \mathrm{L}$ \\
\hline Saccharomyces cerevisiae & \multicolumn{4}{|c|}{$17 / 83$} \\
\hline Saccharomyces boulardii & \multicolumn{4}{|c|}{ 9/91 } \\
\hline Komagataella pastoris & $1 / 99$ & \multicolumn{3}{|l|}{ 0/100 } \\
\hline Torulaspora delbrueckii & & $70 / 30$ & $52 / 48$ & $36 / 64$ \\
\hline Yarrowia lipolytica & \multicolumn{4}{|c|}{$5 / 95$} \\
\hline Debaryomyces hansenii & $7 / 93$ & \multicolumn{3}{|l|}{ 2/98 } \\
\hline Candida boidinii & $3 / 97$ & \multicolumn{3}{|l|}{$2 / 98$} \\
\hline Starmerella bombicola & $1 / 99$ & \multicolumn{3}{|l|}{$0 / 100$} \\
\hline Kluyveromyces marxianus & & $74 / 26$ & $75 / 25$ & $69 / 31$ \\
\hline Xanthophyllomyces dendrorhous & $4 / 96$ & \multicolumn{3}{|l|}{$0 / 100$} \\
\hline Cryptococcus curvatus & & \multicolumn{3}{|l|}{$8 / 92$} \\
\hline Sporidiobolus johnsonii & & \multicolumn{3}{|l|}{$32 / 68$} \\
\hline Aspergillus niger & \multicolumn{3}{|c|}{$16 / 84^{2}$} & \\
\hline Geotrichum candidum & $37 / 63$ & \multicolumn{3}{|l|}{$3 / 97$} \\
\hline Penicillium camemberti & & $100 / 0$ & $1 / 99$ & $0 / 100$ \\
\hline Penicillium roqueforti & & $41 / 59$ & $11 / 89$ & $2 / 98$ \\
\hline Penicillium adametzii & \multicolumn{4}{|c|}{$37 / 63$} \\
\hline Penicillium corylophilum & \multicolumn{4}{|c|}{$9 / 91$} \\
\hline
\end{tabular}

${ }^{1}$ obtained by GC-analysis; ${ }^{2}$ dihydrocoumarin and coumarin are only the $38 \%$ of the biotransformation mixture.

The yeasts Komagataella pastoris, Starmerella bombicola and the basidiomycota Xanthophyllomyces dendrorhous are completely inactive with a substrate concentration of $0.6 \mathrm{~g} / \mathrm{L}$. Nevertheless, small amounts of the melilotic acid ( $1 \%, 1 \%$ and $4 \%$, respectively) were detected in the biotransformation mixtures produced with the same strains, using a coumarin concentration of $0.3 \mathrm{~g} / \mathrm{L}$. Similarly, the microorganisms Debaryomyces hansenii, Candida boidinii and Geotrichum candidum increased their biocatalytic activity using the latter substrate concentration. The results obtained with Geotrichum candidum are especially amazing as the melilotic acid/coumarin ratio measured in the fermentation broth increased from 3/97 to 37/63 by simply halving the substrate concentration. These data underlined the impact of the coumarin toxicity on the biotransformation process. 
Moreover, using a starting substrate concentration of $0.6 \mathrm{~g} / \mathrm{L}$, the investigated microbial strains showed biocatalytic activities very different from each other. It is worth noting that our Saccharomyces species (cerevisiae and boulardii) gave the disappointing conversion ratio of 17/83 and 9/91, respectively. These results are in sharp contrast with those reported for other Saccharomyces cerevisiae strains [9], pointing at the possible biocatalytic activity differences among strains of the same species.

In addition, all experiments afforded the melilotic acid and coumarin as main metabolites, except for Aspergillus niger. In this case, the microbial transformation gave the usual melilotic acid/coumarin mixture (16/84 ratio) close to a plethora of unidentified compounds. The GC-MS analysis indicated that only the $38 \%$ of the produced metabolites corresponded to the melilotic acid/coumarin mixture whereas the main part of the formed products are most likely deriving by coumarin oxidation.

Overall, using a substrate concentration of $0.6 \mathrm{~g} / \mathrm{L}$, all the tested microorganisms afforded a melilotic acid/coumarin ratio inferior of 40/60 with the exception of the yeasts Torulaspora delbrueckii, Kluyveromyces marxianus and of the filamentous fungi Penicillium camemberti and Penicillium roqueforti. Thus, we decided to employ only the latter four microorganisms for further biotrasformations, performed using increasing concentration of the substrate. Accordingly, we run two sets of four experiments in which the coumarin concentration was doubled and tripled, to a value of $1.2 \mathrm{~g} / \mathrm{L}$ and $1.8 \mathrm{~g} / \mathrm{L}$, respectively.

The results allowed differentiating the fungal strains based on their biotransformation performances. The yeasts Torulaspora delbrueckii and Kluyveromyces marxianus possess comparable activity at $0.6 \mathrm{~g} / \mathrm{L}$ affording a melilotic acid/coumarin ratio value of $70 / 30$ and $74 / 26$, respectively. However, when the coumarin concentration increases, Torulaspora delbrueckii decreases its biocatalytic efficiency whereas Kluyveromyces marxianus proves to be much less affected by the substrate toxicity. On the contrary, the high level of coumarin strongly inhibited both growth and activity of the Penicillium strains. Penicillium camemberti seems to be the strain most sensitive to coumarin as it completely transformed the substrate at $0.6 \mathrm{~g} / \mathrm{L}$ concentration whereas at 1.2 and $1.8 \mathrm{~g} / \mathrm{L}$ the formation of the melilotic acid was almost completely blocked, respectively. Even less remarkably, Penicillium roqueforti showed the same behavior and the biotransformation experiments led to biotransformation mixtures with a melilotic acid/coumarin ratio that ranged from $41 / 59$ to $2 / 98$ by increasing the coumarin concentration from $0.6 \mathrm{~g} / \mathrm{L}$ to $1.8 \mathrm{~g} / \mathrm{L}$.

Another relevant problem that we faced during our study concerns the evaluation of the actual yields of the biotransformation process. Indeed, the melilotic acid/coumarin ratio indicates the progress of the 'biohydrogenation' reaction but doesn't give the concentration value of the two latter compounds in the fermentation broths. In different experiments, we observed that the extraction/distillation procedure, afforded an amount of the dihydrocoumarin/coumarin mixture noticeably inferior to the amount of the starting substrate.

Aiming to quantify the loss of the substrate, we specially designed a suitable internal standard to be employed for the GC analyses of the biotransformation reactions. This compound should possess chemical/physical characteristics very similar to those of the melilotic acid. In fact, it must have similar solubility in the fermentation broths, it must be extractable using the same solvent and it must give similar response in the GC-MS detector. Therefore, we selected 3-(2-hydroxy-5-methylphenyl)propanoic acid (=6-methyl-melilotic acid) as the most suitable internal standard. The GC-MS analysis of this compound in the mixture with the melilotic acid show two well-resolved peaks corresponding to dihydrocoumarin and 6-methyldihydrocoumarin. In addition, the synthesis of compound 7 can be easily performed starting from the commercially available 6-methyl-coumarin (4) (Figure 3). Accordingly, the chemical hydrogenation of 4 with hydrogen and palladium on charcoal as catalyst afforded the 6-methyl-dihydrocoumarin (5) that was transformed into sodium salt 6 by treatment with sodium hydroxide in ethanol. 


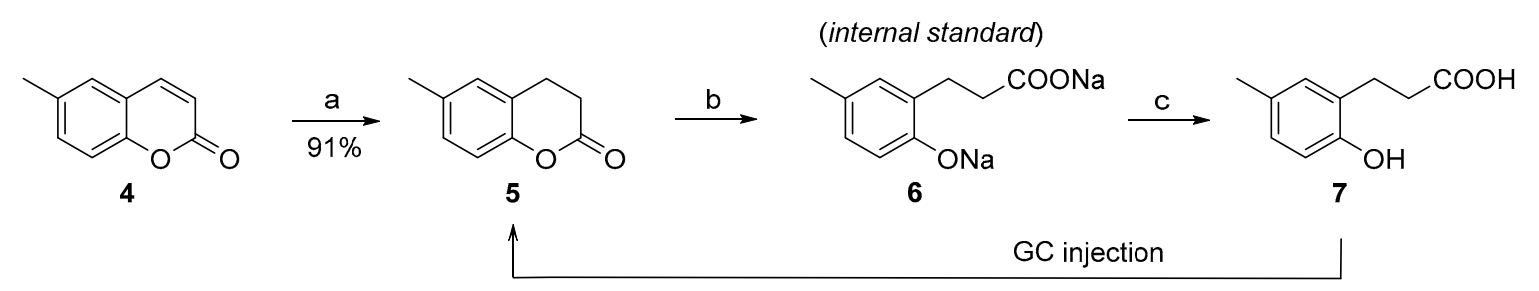

Figure 3. Synthesis of the internal standard 6. Reagents and conditions: (a) $\mathrm{H}_{2}, \mathrm{AcOH}, \mathrm{Pd} / \mathrm{C}$ catalyst, 8 h, r.t.; (b) $\mathrm{NaOH} / \mathrm{EtOH}, 60{ }^{\circ} \mathrm{C}, 10 \mathrm{~min}$; (c) $\mathrm{HCl}$ aq. ( $3 \% \mathrm{w} / \mathrm{v}$ ).

Since compound 5 was obtained in high purity by crystallization and the following transformation into salt $\mathbf{6}$ is quantitative, we use a standard solution of the latter salt in ethanol as internal standard. All the sample were then acidified, were extracted and then were analyzed by GC-MS. The most relevant data resulting from this study are collected in Figure 4. We can observe that different strains, besides performing biohydrogenation of the conjugated double bond, further degraded the coumarin/melilotic acid.

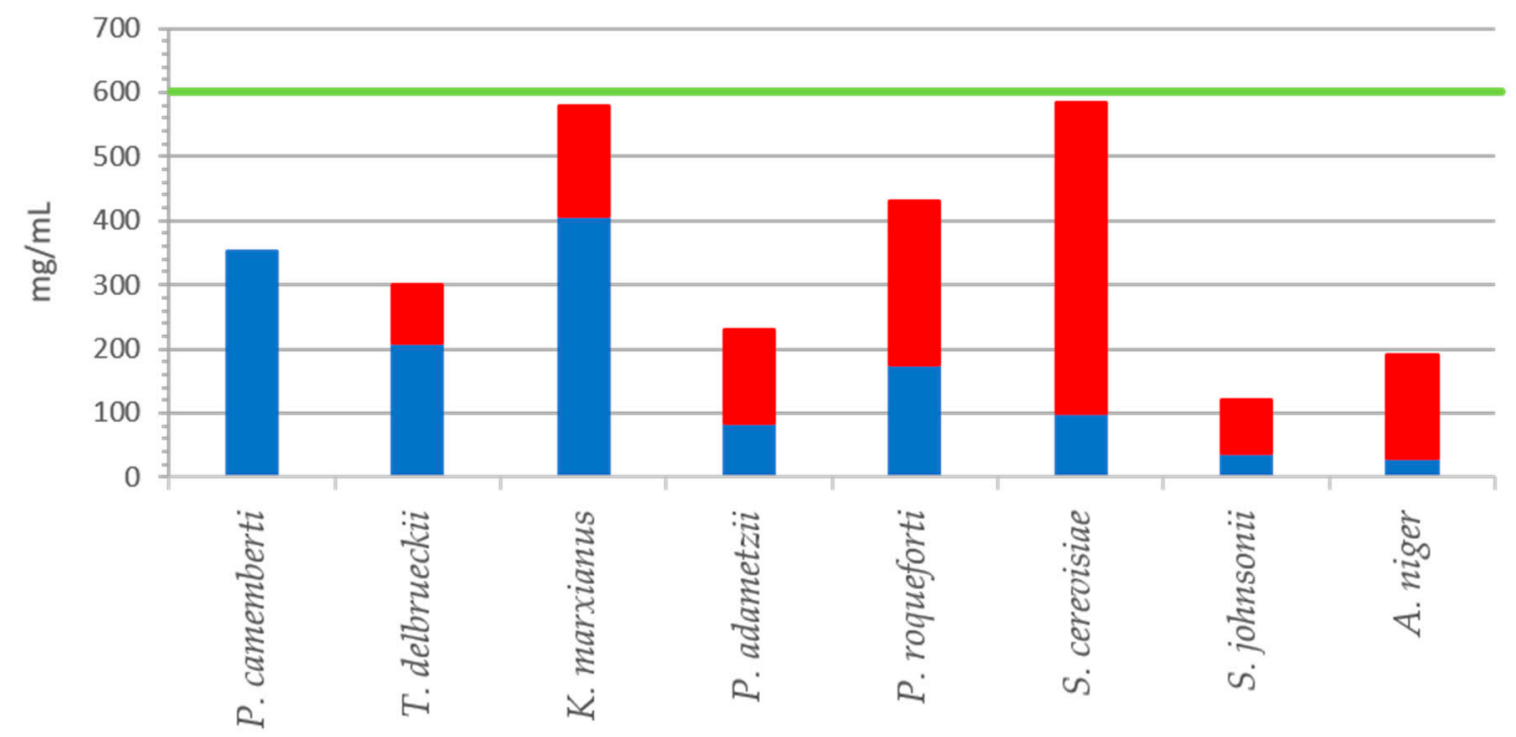

Figure 4. Determination of the dihydrocoumarin (blue bar) and coumarin (red bar) titer after seven days of fermentation and using ethanolic solution of 6 as an internal standard. The starting coumarin concentration was $0.6 \mathrm{~g} / \mathrm{L}$ (green line).

Despite this fact, only Aspergillus niger afforded a number of detectable metabolites, whereas the analysis of the biotransformation mixtures obtained using the other strains allowed to detect only the presence of the melilotic acid and coumarin. Therefore, it is reasonable to assume that some species can completely degrade the studied phenylpropanoids through different metabolic pathways. This is the case of the fermentation experiment performed with Sporidiobolus johnsonii and Penicillium adametzii, where more than half of the starting coumarin was completely consumed after seven days. Though in a less pronounced way, also Penicillium camemberti, Torulaspora delbrueckii and Penicillium roqueforti were able to degrade coumarin whereas we didn't observe these side reactions employing Kluyveromyces marxianus and Saccharomyces cerevisiae.

It is worth noting that the kinetics of the double bond saturation, of the dihydrocoumarin hydrolysis and of the phenylpropanoids degradation can be different from one microorganism to another. In order to acquire comparable data, we selected uniform conditions and a specific transformation time of seven days. Therefore, these results suggest the possibility to improve the biotransformation process by the optimization of the experimental conditions, based on the characteristics of the used strain. 


\section{Materials and Methods}

\subsection{Materials and General Methods}

All air and moisture sensitive reactions were carried out using dry solvents and under a static atmosphere of nitrogen. All solvents and reagents were of commercial quality and were purchased from Sigma-Aldrich (St. Louis, MO, USA).

Coumarin and 6-methyl-coumarin were purchased from Sigma-Aldrich.

The following reference standard compounds were synthesized in our laboratory and were used either for the unambiguous identification of the compounds formed in the biotransformation experiments or as an internal standard for the determination of the transformation yields.

Dihydrocoumarin (2) was prepared by the hydrogenation of coumarin at atmospheric pressure, using the acetic acid as a solvent and $\mathrm{Pd} / \mathrm{C}$ as a catalyst [42]. After the work up procedure, the crude product was purified by the bulb-to-bulb distillation. The obtained colourless oil showed the following analytic data:

Dihydrocoumarin (2) $=($ Chroman-2-one $)$

${ }^{1} \mathrm{H}$ NMR $\left(400 \mathrm{MHz}, \mathrm{CDCl}_{3}\right): \delta=7.28-7.16(\mathrm{~m}, 2 \mathrm{H}), 7.13-7.01(\mathrm{~m}, 2 \mathrm{H}), 3.00($ br t $, J=7.3 \mathrm{~Hz}, 2 \mathrm{H})$, $2.78($ br t, $J=7.3 \mathrm{~Hz}, 2 \mathrm{H})$.

${ }^{13} \mathrm{C}$ NMR $\left(100 \mathrm{MHz}, \mathrm{CDCl}_{3}\right): \delta=168.4(\mathrm{C}), 151.9(\mathrm{C}), 128.2(\mathrm{CH}), 127.9(\mathrm{CH}), 124.3(\mathrm{CH}), 122.6(\mathrm{C})$, $116.8(\mathrm{CH}), 29.1\left(\mathrm{CH}_{2}\right), 23.6\left(\mathrm{CH}_{2}\right)$.

GC-MS (EI): $\mathrm{m} / z(\%)=148\left[\mathrm{M}^{+}\right]$(100), 120 (84), 106 (10), 91 (75), 78 (47), 63 (12), 51 (15).

Melilotic acid (3) was prepared by the treatment of dihydrocoumarin with $\mathrm{NaOH}$ in ethanol at a reflux for one hour. The main part of the solvent was removed by evaporation under reduced pressure and the residue was cooled at $0{ }^{\circ} \mathrm{C}$. Diluted $\mathrm{HCl}$ aq. $(3 \% \mathrm{w} / \mathrm{v})$ was added dropwise until the $\mathrm{pH}$ of the mixture was comprised between the values of 5 and 6 . The reaction was then extracted with ethyl acetate and the organic phase was concentrated under reduced pressure. The residue was purified by chromatography using the $n$-hexane/AcOEt mixture as an eluent to afford a pale yellow thick oil consisting of a 92:8 mixture (by NMR analysis) of melilotic acid and dihydrocoumarin, respectively.

Melilotic acid (3) $=$ (3-(2-hydroxyphenyl)propanoic acid)

${ }^{1} \mathrm{H}$ NMR $\left(400 \mathrm{MHz}, \mathrm{CDCl}_{3}\right): \delta=9.08$ (br s, $\left.2 \mathrm{H}\right), 7.13-7.01(\mathrm{~m}, 2 \mathrm{H}), 6.89-6.77(\mathrm{~m}, 2 \mathrm{H}), 2.92$ (br t, $J=7.1 \mathrm{~Hz}, 2 \mathrm{H}), 2.74(\mathrm{brt}, J=7.1 \mathrm{~Hz}, 2 \mathrm{H})$.

${ }^{13} \mathrm{C}$ NMR $\left(100 \mathrm{MHz}, \mathrm{CDCl}_{3}\right): \delta=180.1(\mathrm{C}), 153.8(\mathrm{C}), 130.3(\mathrm{CH}), 127.9(\mathrm{CH}), 126.7(\mathrm{CH}), 120.8(\mathrm{C})$, $116.3(\mathrm{CH}), 34.4\left(\mathrm{CH}_{2}\right), 24.8\left(\mathrm{CH}_{2}\right)$.

MS (ESI): $189.0\left(\mathrm{M}+\mathrm{Na}^{+}\right) ; 164.9\left(\mathrm{M}-\mathrm{H}^{+}\right)$.

GC-MS (EI): The GC-MS analysis of the melilotic acid shows a single peak with the retention time and mass spectra identical to those recorded for dihydrocoumarin.

6-Methyl-dihydrocoumarin (5) was prepared by the hydrogenation of 6-methyl-coumarin (4) at an atmospheric pressure, using the acetic acid as a solvent and $\mathrm{Pd} / \mathrm{C}$ as a catalyst. After the work up procedure, the crude product was purified by chromatography using the $n$-hexane/AcOEt mixture as an eluent to afford pure 5 as a colorless solid, showing the following analytic data:

6-Methyl-dihydrocoumarin (5) = (6-methylchroman-2-one)

M.p: $78-80^{\circ} \mathrm{C}$

${ }^{1} \mathrm{H} \mathrm{NMR}\left(400 \mathrm{MHz}, \mathrm{CDCl}_{3}\right): \delta=7.04(\mathrm{dm}, J=8.2 \mathrm{~Hz}, 1 \mathrm{H}), 6.99(\mathrm{br} \mathrm{s}, 1 \mathrm{H}), 6.94(\mathrm{~d}, J=8.2 \mathrm{~Hz}, 1 \mathrm{H})$, 2.99-2.92 (m, 2H), 2.80-2.73 (m, 2H), $2.32(\mathrm{~s}, 3 \mathrm{H})$.

${ }^{13} \mathrm{C}$ NMR $\left(100 \mathrm{MHz}, \mathrm{CDCl}_{3}\right): \delta=168.7(\mathrm{C}), 149.9(\mathrm{C}), 134.0(\mathrm{C}), 128.7(\mathrm{CH}), 128.4(\mathrm{CH}), 122.3(\mathrm{C})$, $116.6(\mathrm{CH}), 29.3\left(\mathrm{CH}_{2}\right), 23.7\left(\mathrm{CH}_{2}\right), 20.7(\mathrm{Me})$.

GC-MS (EI): $\mathrm{m} / \mathrm{z}(\%)=162\left[\mathrm{M}^{+}\right]$(100), 134 (83), 120 (23), 105 (13), 91 (77), 77 (17), 65 (13), 51 (16). 


\subsection{Analytical Methods and Characterization of the Products Deriving from the Biotransformation Experiments}

\subsubsection{Instruments and Analytic Condition}

Nuclear Magnetic Resonance spectroscopy (NMR): ${ }^{1} \mathrm{H}$ and ${ }^{13} \mathrm{C}-\mathrm{NMR}$ spectra and DEPT experiments were recorded in $\mathrm{CDCl}_{3}$ solutions at rt using a Bruker-AC-400 spectrometer at $400 \mathrm{MHz}$, $100 \mathrm{MHz}$ and $100 \mathrm{MHz}$, respectively; ${ }^{13} \mathrm{C}$ spectra are proton decoupled; chemical shifts are in ppm relative to internal $\mathrm{SiMe}_{4}(=0 \mathrm{ppm})$.

TLC: Merck silica gel $60 F_{254}$ plates (Merck Millipore, Milan, Italy). Column chromatography: Silica gel.

Melting points were measured on a Reichert apparatus (Reichert, Vienna, Austria), equipped with a Reichert microscope, and are uncorrected.

Mass spectrum were recorded on a Bruker ESQUIRE 3000 PLUS spectrometer (ESI detector) (Billerica, MA, USA) or by GC-MS analyses.

GC-MS analyses: HP-6890 gas chromatograph equipped with a 5973 mass detector, using a HP-5MS column ( $30 \mathrm{~m}^{\prime} 0.25 \mathrm{~mm}, 0.25 \mu \mathrm{m}$ film thickness; Hewlett Packard, Palo Alto, CA, USA) with the following temp. program: $38^{\circ}(9 \mathrm{~min})-3^{\circ} / \mathrm{min}-90^{\circ}(1 \mathrm{~min})-6^{\circ} / \mathrm{min}-180^{\circ}(1 \mathrm{~min})-15^{\circ} / \mathrm{min}-$ $280^{\circ}$ ( $5 \mathrm{~min}$ ); carrier gas, He; constant flow $1 \mathrm{ml} / \mathrm{min}$; split ratio, $1 / 30$; $t_{\mathrm{R}}$ given in $\mathrm{min}$ :

$t_{\mathrm{R}}(\mathbf{1}) 37.78, t_{\mathrm{R}}(\mathbf{2}) 36.26, t_{\mathrm{R}}(\mathbf{5}) 39.07$.

The biotransformation reactions were analyzed using two different procedures depending on whether the internal standard was used or not.

\subsubsection{Extraction/Analysis Procedure (without Internal Standard)}

The biotransformation broth was treated at $0{ }^{\circ} \mathrm{C}$ with a concentrated $\mathrm{HCl}$ aq. $(37 \% \mathrm{w} / \mathrm{v})$ in order to bring the $\mathrm{pH}$ between 3 and 4 . Ethyl acetate (about one fourth of the volume of the broth) was added and the mixture was filtered on a celite pad. The celite-biomass cake was washed with acetate, the phases were separated and the aqueous phase was extracted with further solvent. The combined organic phases were dried $\left(\mathrm{Na}_{2} \mathrm{SO}_{4}\right)$ and concentrated under reduced pressure. The residue was analyzed using different methods. The TLC analysis showed the absence of dihydrocoumarin and the presence of the melilotic acid and/or of coumarin the in the crude biotrasformation mixture. The NMR analysis allows measuring the coumarin/melilotic acid ratio in the crude biotrasformation mixture. The GC-MS analysis gave a dihydrocoumarin/coumarin ratio (Table 1). In these analyses, the dihydrocoumarin and coumarin GC peaks area were directly proportional to the concentration of the melilotic acid and coumarin, respectively. Most likely, when the sample is introduced in the GC injector, melilotic acid is quantitatively transformed into dihydrocoumarin whereas coumarin goes through the column unaffected. The GC-MS results are in good agreements with those obtained by the NMR analysis of the same samples, thus confirming that both analytical methods are suitable for the determination of the melilotic acid and coumarin concentration in the fermentation broths.

\subsubsection{Quantitative Analysis Procedure (with Internal Standard)}

A solution of disodium salt of 3-(2-hydroxy-5-methylphenyl)propanoic acid in ethanol was prepared by filling a $5 \mathrm{~mL}$ volumetric flask contained $100 \mathrm{mg}$ of 6-methyl-dihydrocoumarin with a solution of $\mathrm{NaOH}(5 \% \mathrm{w} / \mathrm{v})$ in absolute ethanol. The resulting pale-yellow solution was heated at $60^{\circ} \mathrm{C}$ for $10 \mathrm{~min}$ and then was stored at $4{ }^{\circ} \mathrm{C}$ before the use. The latter solution $(500 \mu \mathrm{L})$ was added to a $40 \mathrm{~mL}$ sample of the biotransformation broth. The mixture was stirred ad $\mathrm{rt}$ and acidified (final $\mathrm{pH} 3-4)$ by the dropwise addition of a concentrated $\mathrm{HCl}$ aq. $(37 \% \mathrm{w} / \mathrm{v})$. Ethyl acetate $(10 \mathrm{~mL})$ was added and the mixture was vigorously stirred for half an hour. The mixture was then centrifuged for $5 \mathrm{~min},\left({ }^{\circ} \mathrm{C}, 3220 \mathrm{~g}\right)$ and the organic phase was collected, dried $\left(\mathrm{Na}_{2} \mathrm{SO}_{4}\right)$ and analyzed by GC-MS. The 6-methyl-dihydrocoumarin peak (internal standard) correspond to a concentration of $250 \mathrm{mg} / \mathrm{L}$ of the same compound in the fermentation broth. 


\subsection{Microorganisms and Biotransformation Experiments}

\subsubsection{Microorganisms and Media}

Saccharomyces cerevisiae (Type II YSC2, Lot BCBR1308) was purchased from Sigma-Aldrich (St. Louis, MO, USA).

Saccharomyces boulardii (probiotic strain SB80 ${ }^{\circledR}$, I-3799) was purchased from AR Fitofarma s.r.1 (Assago, Italy).

Penicillium camemberti (DSM 1233), Geotrichum candidum (DSM 10452), Komagataella pastoris (DSM 70382), Yarrowia lipolytica (DSM 8218), Torulaspora delbrueckii (DSM 70483), Debaryomyces hansenii (DSM 70590), Candida boidinii (DSM 70026), Starmerella bombicola (DSM 27465), Kluyveromyces marxianus (DSM 70073), Xanthophyllomyces dendrorhous (DMS 5626), Cryptococcus curvatus (DSM 70022) and Sporidiobolus johnsonii (DSM 70580) were purchased from DSMZ GmbH collection (Braunschweig, Germany).

Aspergillus niger (CBS 626.26) was purchased from the CBS-KNAW collection (Utrecht, The Netherlands).

Penicillium adametzii (ATCC 10407) was purchased from the ATCC collection (Mannanas, VA, USA).

Penicillium corylophilum (MUT 5838) and Penicillium roqueforti (MUT 5856) were isolated as axenic cultures in our laboratory, then identified by the Mycotheca Universitatis Taurinensis (MUT) of the University of Turin and finally deposited in the same institution under the collection number given in brackets.

The biotransformation experiments were performed using two different media, namely the universal Medium for Yeasts (YM) and Malt Extract Medium (MEM), depending on the microorganism used.

YM composition: yeast extract ( $3 \mathrm{~g} / \mathrm{L})$, malt extract (3 g/L), peptone from soybeans ( $5 \mathrm{~g} / \mathrm{L})$, glucose $(10 \mathrm{~g} / \mathrm{L})$.

MEM composition: glucose (20 g/L), malt extract (20 g/L), peptone from soybeans (2 g/L).

YM was used for Saccharomyces cerevisiae, Saccharomyces boulardii, Komagataella pastoris, Torulaspora delbrueckii, Yarrowia lipolytica, Debaryomyces hansenii, Candida boidinii, Starmerella bombicola, Kluyveromyces marxianus, Xanthophyllomyces dendrorhous, Cryptococcus curvatus and Sporidiobolus johnsonii.

MEM was used for Geotrichum candidum, Aspergillus niger, Penicillium camemberti, Penicillium roqueforti, Penicillium adametzii and Penicillium corylophilum.

All the biotransformations were carried out in triplicate and the presented results are the media of three experimental data.

The experimental conditions used for the biotransformations are based on the type of microorganism used. We used two main general procedures related to the different morphological features of the active grow mycelia.

3.3.2. General Procedure for the Biotransformation of Coumarin Using Microorganisms with Yeast-Shape Mycelium (Saccharomyces cerevisiae, Saccharomyces boulardii, Komagataella pastoris, Torulaspora delbrueckii, Yarrowia lipolytica, Debaryomyces hansenii, Candida boidinii, Starmerella bombicola, Kluyveromyces marxianus, Xanthophyllomyces dendrorhous, Cryptococcus curvatus, Sporidiobolus johnsonii and Geotrichum candidum)

A small amount of active mycelium was picked-up from a petri dish, was suspended in $1 \mathrm{~mL}$ of sterile water and then was inoculated in a $100 \mathrm{~mL}$ conical pyrex flask containing $40 \mathrm{~mL}$ of the suitable medium. The flask was shaken for three days at $28{ }^{\circ} \mathrm{C}$ and $140 \mathrm{rpm}$ (with the exception of Xanthophyllomyces dendrorhous, Geotrichum candidum and Saccharomyces boulardii that were grown at $20^{\circ} \mathrm{C}, 25^{\circ} \mathrm{C}$ and $37^{\circ} \mathrm{C}$, respectively). After this period, the cells were centrifuged for $5 \mathrm{~min},\left(4^{\circ} \mathrm{C}\right.$, $3220 \mathrm{~g}$ ) and collected, removing the medium. The cells were suspended in $3 \mathrm{~mL}$ of sterile water and were inoculated in a $1 \mathrm{~L}$ conical biotransformation flask containing $400 \mathrm{~mL}$ of fresh medium. In order to ensure aerobic conditions, the flask was sealed with a cellulose plug. The microorganism was grown in the same conditions described before for two days and then was treated with the suitable amount of a $300 \mathrm{~g} / \mathrm{L}$ solution of coumarin in dry DMSO. The flask was then shaken at the indicated temperature and $140 \mathrm{rpm}$ for seven days before performing the work-up and isolation procedures. 
3.3.3. General Procedure for the Biotransformation of Coumarin Using Microorganisms with Spore-Forming Mycelium (Aspergillus niger, Penicillium camemberti, Penicillium roqueforti, Penicillium adametzii and Penicillium corylophilum)

In the case of the spore-forming mycelium, the spores were collected from a fully sporulated surface of a culture grown on a $90 \mathrm{~mm}$ in the diameter potato dextrose agar (PDA) plate and were then suspended in $10 \mathrm{~mL}$ of sterile water. After that, $1 \mathrm{~mL}$ of the same suspension was used to inoculate a $1 \mathrm{~L}$ conical biotransformation flask containing $400 \mathrm{~mL}$ of the suitable medium. In order to ensure aerobic conditions, the flask was sealed with a cellulose plug. The flask was shaken for three days at $25^{\circ} \mathrm{C}$ and $140 \mathrm{rpm}$ and then was treated with the suitable amount of a $300 \mathrm{~g} / \mathrm{L}$ solution of coumarin in dry DMSO. The biotransformation was performed at $25^{\circ} \mathrm{C}$ and $140 \mathrm{rpm}$ for seven days before proceeding with the work-up and isolation procedure.

\subsubsection{Isolation of the Dihydrocoumarin from the Fermentation Broth by Steam Distillation}

The biotransformation was stopped by cooling the fermentation broth $(400 \mathrm{~mL})$ at $0{ }^{\circ} \mathrm{C}$ and by the addition of citric acid in order to bring the $\mathrm{pH}$ between 3 and 4 . The mixture was steam distilled until the coumarin and/or dihydrocoumarin content in the last distillate fraction, were no longer detectable by the TLC analysis. The combined distillate fractions were saturated with $\mathrm{NaCl}$ and extracted with $\mathrm{CH}_{2} \mathrm{Cl}_{2}(3 \times 100 \mathrm{~mL})$. The combined organic phases were dried $\left(\mathrm{Na}_{2} \mathrm{SO}_{4}\right)$ and concentrated under reduced pressure. The residue is a brown oil consisting of a nearly pure dihydrocoumarin/coumarin mixture. Pure dihydrocoumarin can be obtained by chromatographic purification of the latter oil, using the $n$-hexane $/ \mathrm{Et}_{2} \mathrm{O}$ mixture as an eluent.

\subsubsection{Isolation of the Dihydrocoumarin from the Fermentation Broth by}

Extraction-Distillation Procedure

The biotransformation was stopped by cooling the fermentation broth $(400 \mathrm{~mL})$ at $0{ }^{\circ} \mathrm{C}$ and by treatment with concentrated $\mathrm{HCl}$ aq. $(37 \% \mathrm{w} / \mathrm{v})$ in order to bring the $\mathrm{pH}$ between 3 and 4 . Ethyl acetate $(100 \mathrm{~mL})$ was added and the mixture was filtered on a celite pad. The celite-biomass cake was washed with acetate, the phases were separated and the aqueous phase was extracted with further solvent. The combined organic phases were dried $\left(\mathrm{Na}_{2} \mathrm{SO}_{4}\right)$ and concentrated under reduced pressure. The residue was treated with a catalytic amount of citric acid $(20 \mathrm{mg})$ and the mixture was distilled under reduced pressure. The obtained pale yellow oil consists of a nearly pure dihydrocoumarin/coumarin mixture. Pure dihydrocoumarin can be obtained by chromatographic purification of the latter oil, using the $n$-hexane $/ \mathrm{Et}_{2} \mathrm{O}$ mixture as an eluent.

\section{Conclusions}

Our work provides some relevant findings. The ability of different yeasts and filamentous fungi to reduce the conjugated double bond of the coumarin was screened. We demonstrated that all the eighteen investigated species are able to convert the substrate, although with very different conversion rates and different sensitivity to the coumarin concentration. The yeasts Torulaspora delbrueckii, Kluyveromyces marxianus and the fungus Penicillium camemberti displayed the highest activity and selectivity during the substrate transformation. Among the latter strains, Kluyveromyces marxianus presented the best resistance to the substrate toxicity, allowing the biotransformation process even with a coumarin concentration up to $1.8 \mathrm{~g} / \mathrm{L}$. Finally, we observed that some microorganisms can also further degrade coumarin and/or dihydrocoumarin, lowering the overall biotransformation yields.

Author Contributions: S.S. conceived this study; S.S., A.C. and M.V. equally contributed to the design and performed the experiments as well as analyzed the data; S.S wrote the paper.

Funding: This research was funded by [Regione Lombardia], grant number [228775 VIPCAT (Value Added Innovative Protocols for Catalytic Transformations)].

Acknowledgments: The authors thank Regione Lombardia for supporting this study within the project POR-FESR 2014-2020 n 228775 VIPCAT (Value Added Innovative Protocols for Catalytic Transformations). 
Conflicts of Interest: The authors declare no conflict of interest.

\section{References}

1. Surburg, H.; Panten, J. Common Fragrance and Flavor Materials: Preparation, Properties and Uses, 6th ed.; Wiley: Hoboken, NJ, USA, 2016; ISBN 9783527331604.

2. Schreier, P.; Wörner, M. Flüchtige inhaltsstoffe aus tonkabohnen (Dipteryx odorata Willd.). Eur. Food Res. Technol. 1991, 193, 21-25.

3. Authority, E.F.S. Opinion of the scientific panel on food additives, flavourings, processing aids and materials in contact with food (AFC) related to coumarin. EFSA J. 2004, 104, 1-36. [CrossRef]

4. Kovaleva, A.M.; Grud'Ko, I.V.; Aleksandrov, A.N.; Komissarenko, A.N. GC/MS study of the chloroform fraction of Melilotus officinalis. Chem. Nat. Compd. 2009, 45, 585-586. [CrossRef]

5. Regulation (Ec), No. 1334/2008 of the European Parliament and of The Council of 16 December 2008 on flavourings and certain food ingredients with flavouring properties for use in and on foods and amending Council Regulation (EEC) No.1601/91, Regulations (EC) No. 2232/96 and (EC) No. 110/2008 and Directive 2000/13/EC. Off. J. Eur. Union 2008, L 354/34.

6. U.S. Food \& Drugs Administration. Code of Federal Regulations-Title 21-Food and Drugs; U.S. Government Publishing Office: Washington, DC, USA, 2018.

7. Serra, S.; Fuganti, C.; Brenna, E. Biocatalytic preparation of natural flavours and fragrances. Trends Biotechnol. 2005, 23, 193-198. [CrossRef] [PubMed]

8. Brenna, E.; Fronza, G.; Fuganti, C.; Gatti, F.G.; Grande, V.; Serra, S.; Guillou, C.; Reniero, F.; Serra, F. Stable Isotope Characterization of the ortho-Oxygenated Phenylpropanoids: Coumarin and Melilotol. J. Agric. Food Chem. 2005, 53, 9383-9388. [CrossRef] [PubMed]

9. Häser, K.; Wenk, H.H.; Schwab, W. Biocatalytic Production of Dihydrocoumarin from Coumarin by Saccharomyces cerevisiae. J. Agric. Food Chem. 2006, 54, 6236-6240. [CrossRef]

10. Aguirre-Pranzoni, C.; Orden, A.A.; Bisogno, F.R.; Ardanaz, C.E.; Tonn, C.E.; Kurina-Sanz, M. Coumarin metabolic routes in Aspergillus spp. Fungal Biol. 2011, 115, 245-252. [CrossRef]

11. Aguirre-Pranzoni, C.B. Biotransformation of dihydrocoumarin by Aspergillus niger ATCC 11394. Org. Chem. Argent. 2011, 2011, 170-181.

12. Marumoto, S.; Miyazawa, M. Microbial reduction of coumarin, psoralen, and xanthyletin by Glomerella cingulata. Tetrahedron 2011, 67, 495-500. [CrossRef]

13. Attia, G.A.; Abou-El-Seoud, K.A.; Ibrahim, A.-R.S. Biotransformation of coumarins by Cunninghamella elegans. Afr. J. Pharm. Pharmacol. 2016, 10, 411-418.

14. Jainara, N.; Joao, C.; Eliane, S. Biotransformation of coumarins by filamentous fungi: An alternative way for achievement of bioactive analogs. Mini-Rev. Org. Chem. 2018, 15, 1-10.

15. Toogood, H.S.; Scrutton, N.S. Discovery, Characterisation, Engineering and Applications of Ene Reductases for Industrial Biocatalysis. ACS Catal. 2018, 8, 3532-3549. [CrossRef] [PubMed]

16. Fronza, G.; Fuganti, C.; Pinciroli, M.; Serra, S. Stereochemical aspects of the bioreduction of the conjugated double bond of perillaldehyde. Tetrahedron Asymmetry 2004, 15, 3073-3077. [CrossRef]

17. Serra, S.; Fuganti, C.; Gatti, F.G. A Chemoenzymatic, Preparative Synthesis of the Isomeric Forms of $p$-Menth-1-en-9-ol: Application to the Synthesis of the Isomeric Forms of the Cooling Agent 1-Hydroxy-2,9-cineole. Eur. J. Org. Chem. 2008, 2008, 1031-1037. [CrossRef]

18. Fronza, G.; Fuganti, C.; Serra, S. Stereochemical Course of Baker's Yeast Mediated Reduction of the Tri- and Tetrasubstituted Double Bonds of Substituted Cinnamaldehydes. Eur. J. Org. Chem. 2009, 2009, 6160-6171. [CrossRef]

19. Csuk, R.; Glaenzer, B.I. Baker's yeast mediated transformations in organic chemistry. Chem. Rev. 1991, 91, 49-97. [CrossRef]

20. Serra, S.; Piccioni, O. A new chemo-enzymatic approach to the stereoselective synthesis of the flavors tetrahydroactinidiolide and dihydroactinidiolide. Tetrahedron Asymmetry 2015, 26, 584-592. [CrossRef]

21. Serra, S. Recent Advances in the Synthesis of Carotenoid-Derived Flavours and Fragrances. Molecules 2015, 20, 12817-12840. [CrossRef]

22. Serra, S.; De Simeis, D.; Brenna, E. Lipase mediated resolution of cis- and trans-linalool oxide (pyranoid). J. Mol. Catal. B Enzym. 2016, 133, S420-S425. [CrossRef] 
23. Serra, S.; De Simeis, D. New insights on the baker's yeast-mediated hydration of oleic acid: The bacterial contaminants of yeast are responsible for the stereoselective formation of $(R)$-10-hydroxystearic acid. J. Appl. Microbiol. 2018, 124, 719-729. [CrossRef] [PubMed]

24. Serra, S.; De Simeis, D. Use of Lactobacillus rhamnosus (ATCC 53103) as Whole-Cell Biocatalyst for the Regioand Stereoselective Hydration of Oleic, Linoleic, and Linolenic Acid. Catalysts 2018, 8, 109. [CrossRef]

25. Serra, S.; De Simeis, D. Fungi-Mediated Biotransformation of the Isomeric Forms of the Apocarotenoids Ionone, Damascone and Theaspirane. Molecules 2018, 24, 19. [CrossRef] [PubMed]

26. Serra, S.; De Simeis, D. Two Complementary Synthetic Approaches to the Enantiomeric Forms of the Chiral Building Block (2,6,6-Trimethyltetrahydro-2H-pyran-2-yl)methanol: Application to the Stereospecific Preparation of the Natural Flavor Linaloyl Oxide. Catalysts 2018, 8, 362. [CrossRef]

27. Bourdichon, F.; Casaregola, S.; Farrokh, C.; Frisvad, J.C.; Gerds, M.L.; Hammes, W.P.; Harnett, J.; Huys, G.; Laulund, S.; Ouwehand, A.; et al. Food fermentations: Microorganisms with technological beneficial use. Int. J. Food Microbiol. 2012, 154, 87-97. [CrossRef] [PubMed]

28. Kerry, R.G.; Patra, J.K.; Gouda, S.; Park, Y.; Shin, H.-S.; Das, G. Benefaction of probiotics for human health: A review. J. Food Drug Anal. 2018, 26, 927-939. [CrossRef]

29. Ben Akacha, N.; Gargouri, M. Microbial and enzymatic technologies used for the production of natural aroma compounds: Synthesis, recovery modeling, and bioprocesses. Food Bioprod. Process. 2015, 94, 675-706. [CrossRef]

30. Dikicioglu, D.; Wood, V.; Rutherford, K.M.; McDowall, M.D.; Oliver, S.G. Improving functional annotation for industrial microbes: A case study with Pichia pastoris. Trends Biotechnol. 2014, 32, 396-399. [CrossRef]

31. Johnson, E.A. Biotechnology of non-Saccharomyces yeasts-The ascomycetes. Appl. Microbiol. Biotechnol. 2013, 97, 503-517. [CrossRef]

32. King, A.; Dickinson, J.R. Biotransformation of monoterpene alcohols by Saccharomyces cerevisiae, Torulaspora delbrueckii and Kluyveromyces lactis. Yeast 2000, 16, 499-506. [CrossRef]

33. Morrissey, J.P.; Etschmann, M.M.W.; Schrader, J.; de Billerbeck, G.M. Cell factory applications of the yeast Kluyveromyces marxianus for the biotechnological production of natural flavour and fragrance molecules. Yeast 2015, 32, 3-16.

34. Bankar, A.V.; Kumar, A.R.; Zinjarde, S.S. Environmental and industrial applications of Yarrowia lipolytica. Appl. Microbiol. Biotechnol. 2009, 84, 847-865. [CrossRef] [PubMed]

35. Ageitos, J.M.; Vallejo, J.A.; Veiga-Crespo, P.; Villa, T.G. Oily yeasts as oleaginous cell factories. Appl. Microbiol. Biotechnol. 2011, 90, 1219-1227. [CrossRef] [PubMed]

36. Jo, Y.S.; An, J.U.; Oh, D.K. $\gamma$-Dodecelactone Production from Safflower Oil via 10-Hydroxy-12(Z)-octadecenoic Acid Intermediate by Whole Cells of Candida boidinii and Stenotrophomonas nitritireducens. J. Agric. Food Chem. 2014, 62, 6736-6745. [CrossRef] [PubMed]

37. Frengova, G.I.; Beshkova, D.M. Carotenoids from Rhodotorula and Phaffia: Yeasts of biotechnological importance. J. Ind. Microbiol. Biotechnol. 2008, 36, 163-180. [CrossRef] [PubMed]

38. Carballeira, J.D.; Álvarez, E.; Sinisterra, J.V. Biotransformation of cyclohexanone using immobilized Geotrichum candidum NCYC49: Factors affecting the selectivity of the process. J. Mol. Catal. B Enzym. 2004, 28, 25-32. [CrossRef]

39. Clark, A.M.; Hufford, C.D. Microbial transformations of the sesquiterpene lactone costunolide. J. Chem. Soc. Perkin Trans. 1979, 1, 3022. [CrossRef]

40. Kermasha, S.; Perraud, X.; Bisakowski, B.; Husson, F. Production of flavor compounds by hydroperoxide lyase from enzymatic extracts of Penicillium sp. J. Mol. Catal. B Enzym. 2002, 19, 479-487. [CrossRef]

41. Creuly, C.; Larroche, C.; Gros, J.-B. Bioconversion of fatty acids into methyl ketones by spores of Penicillium roquefortii in a water-organic solvent, two-phase system. Enzym. Microb. Technol. 1992, 14, 669-678. [CrossRef]

42. Biswas, B.; Sen, P.K.; Venkateswaran, R.V. Bargellini condensation of coumarins. Expeditious route to o-carboxyvinylphenoxyisobutyric acids and application to the synthesis of sesquiterpenes helianane, heliannuol A and heliannuol C. Tetrahedron 2007, 63, 12026-12036. [CrossRef] 